\title{
Dopplerographic Assessment of Vertebral Arteries Hemodynamic in Atlantoaxial Instability
}

\section{Ruslan R Abdullaiev*, Igor A Voronzhev, Rizvan Ya Abdullaiev and Nikolay F Posokhov}

Kharkiv Medical Academy of Postgraduate Education, Ukraine

*Corresponding Author: Rizvan Yagubovich Abdullaiev, Department of Ultrasound

Diagnostics, Kharkov Medical Academy of Postgraduate Education, Ukraine.
Received: November 25, 2021

Published: December 31, 2021

(C) All rights are reserved by Ruslan $\mathbf{R}$

Abdullaiev., et al.

\section{Abstract}

Background: Atlantoaxial instability during rotational head movements is often the cause of hemodynamic disturbances in the vertebral arteries.

Objective: Dopplerographic evaluation of blood flow parameters in vertebral arteries in patients with atlantoaxial instability.

Methods: Doppler ultrasonography of the vertebral arteries (VA) was performed in 36 patients with atlantoaxial instability. The maximum systolic velocity (Vs), end diastolic velocity (Vd), resistance index (RI) and minute flow volume (MFV) in the second and third segments of the VA in the neutral position, with ipsilateral and contralateral rotation of the head were determined.

Results: The RI in the left VA was highest during contralateral head rotation and amounted to $0.71 \pm 0.03$, which is significantly (P $<0.01$ ) higher than in healthy individuals. The same trend in the dynamics of hemodynamic parameters was observed in the right vertebral artery. With contralateral rotation (turn left), Vs in the right VA was $54.9 \pm 5.1 \mathrm{~cm} / \mathrm{sec}$, with ipsilateral rotation (turn right) - $37.4 \pm 3.6 \mathrm{~cm} / \mathrm{sec}(\mathrm{P} \mathrm{lr}<0.01$ ), and in the comparative group - $47.8 \pm 4.3 \mathrm{~cm} / \mathrm{sec}$. The RI in the right VA with contralateral head rotation was $0.70 \pm 0.03$, and with ipsilateral rotation it was $0.69 \pm 0.03$, which is significantly $(\mathrm{P}<0.05)$ higher than in healthy individuals. PI had the highest value in the left VA during contralateral head rotation and was $1.05 \pm 0.07$, which is significantly (P < 0.05) higher than in healthy individuals. The smallest MFV was also recorded in the left VA during contralateral head rotation and was 92 $\pm 10 \mathrm{ml} / \mathrm{min}$ - significantly $(\mathrm{P}<0.05)$ less than in healthy individuals

Conclusion: In atlantoaxial instability, rotational head movements lead to a deterioration in hemodynamic parameters in the third segment of the vertebral arteries in the form of a decrease in the minute volume of blood flow, an increase in resistance and pulsation indices. With ipsilateral rotation of the head, the blood flow velocity in the vertebral artery of the same name decreases, while during contralateral rotation, on the contrary, it increases. The difference in comparison between blood flow indicators on the opposite artery and the results of healthy individuals has a significant value.

Keywords: Hemodynamic; Vertebral Arteries; Cervical Spine

\section{Introduction}

The Atlantoaxial junction is a complex structure connecting the occiput and cervical spine. It provides a wide range of motion in the form of flexion, extension and rotation of the craniocervical junction. The cruciate and pterygoid ligaments provide stability to this segment of the cervical spine. Instability of the atlantoaxial joint is more often congenital, but it also occurs as a result of trauma and degenerative changes. Atlantoaxial instability can occur equally in both genders and can present at any age [1-4]. 
Mitchell J. carried out a meta-analysis of literary sources devoted to the study of the effect of rotational movements of the neck on vertebral arteries blood flow [5]. A literature review suggests that pulsed Doppler scanning with color flow imaging is preferable for vertebral artery (VA) blood flow as it provides accurate vessel imaging and hemodynamic recording. For the examinee, it is recommended to use a sitting position that is optimal for access to all VA segments, as well as for monitoring the rotation of the cervical spine during registration of blood flow in the artery. It was shown that the blood flow velocity in VA in patients with pathology of the upper cervical spine during rotation of the neck to the opposite side is higher than in healthy people. In this case, the blood flow velocity increases in the sitting position of the patient and in the intracranial part of the VA more than in the extracranial part. In this regard, the authors of the publications recommend avoiding prolonged head rotation in a wide range and rotational manipulations with a rapid push until there is a more reliable evidence base for clinical practice.

Albuquerque F.C., et al. observed the development of acute vertebrobasilar insufficiency up to ischemic stroke during medical manipulations on the neck with sharp extension and flexion of the head in patients with pathologies of the cervical vertebrae [6]. Bulut M.D. in., et al. (2016) recorded a decrease in the blood flow velocity in the third segment of the vertebral artery in patients with reduced lordosis [7]. A. Brett., et al. in a study of blood flow in healthy people at the level of the atlanto-axial joint, in the suboccipital part of the 3rd segment of the vertebral artery at rest and when bending the head to the right and left found no significant changes [8]. Other authors also suggest that in patients without pre-existing pathologies of the cervical spine, rotational movements in the neck do not lead to significant hemodynamic changes in the vertebral arteries [9].

Cui K. Q., et al. 2016, the blood flow in the third segment of the vertebral artery at the C1-C2 level was studied using functional loads in the form of neck rotation in 6 macaque monkeys. It was revealed that contralateral rotation, extension in combination with ipsi and contralateral rotation, as well as extension in combination with ipsi and contralateral rotation and traction simultaneously lead to a decrease in peak systolic, end diastolic velocity and an increase in the resistance index in the vertebral artery [10].

Erhardt J.W., et al. (2015) studied the effect of a fast push in the area of the atlanto-axial joint on hemodynamics in the vertebral artery in 23 volunteers. The authors recorded the maximum systolic and end-diastolic velocities in 3 cycles in 11 before and after a push, and in 12 without a push. In patients with manipulation, the end diastolic velocity was significantly lower than in the control group [8].

The contradiction in literature data on the change in hemodynamic parameters of blood flow in the vertebral arteries with various neck movements indicates the urgency of this problem and the search for ways to solve it.

\section{Objective}

Dopplerographic evaluation of blood flow parameters in vertebral arteries in patients with atlantoaxial instability.

\section{Materials and Methods}

Doppler ultrasonography of the vertebral arteries (VA) was performed in 36 patients aged 18-44 years (on average $29 \pm 6$ years), in whom atlantoaxial instability was diagnosed by X-ray. The age of the subjects varied within 19-43 years, there were 21 men, 15 women. The maximum systolic velocity (Vs), end diastolic velocity (Vd), resistance index (RI) and minute flow volume (MFV) in the second and third segments of the VA in the neutral position, with ipsilateral and contralateral rotation of the head was determined. The comparative group (CG) consisted of 37 people aged 18 to 35 years (on average $27 \pm 5$ years) without pathology of the cervical spine. Statistical analysis consisted in unvaried comparisons of unpaired groups, performed with the Fisher's exact test for categorical data. The significance level, two-tailed, was set at $\leq 0.05$ for moderately significant, at $\leq 0.01$ for significant and at $\leq 0.001$ for highly significant.

\section{Results}

The blood flow was recorded in the second segment of both vertebral arteries (VA) at the C2-C3 level in the neutral position, when turning to the left and to the right. The average Vs value in patients of the CG was highest in the left VA in the neutral position $(50.3 \pm 4.9 \mathrm{~cm} / \mathrm{sec})$, and the lowest when the head was turned to the right $(43.7 \pm 4.1 \mathrm{~cm} / \mathrm{sec})$. The resistance index (RI) was lowest in LVA in the neutral position $(0.57 \pm 0.02)$, the highest in RVA in the position of turn left ( $0.63 \pm 0.02)$, PI was the lowest $(0.83 \pm 0.04)$ in LVA in position Neutral, the largest - in RVA in the position of turn right $(0.89 \pm 0.04)$, the minute flow volume (MFV) was greatest $(129 \pm 14 \mathrm{ml} / \mathrm{min})$ in the neutral position, the smallest $(112 \pm 11$ 
$\mathrm{ml} / \mathrm{min}$ ) in the position of turn left. It should be noted that there were no significant differences between hemodynamic parameters in the vertebral arteries of healthy goup during rotational head movements.

\begin{tabular}{|c|c|c|c|c|c|c|c|}
\hline \multirow{2}{*}{$\begin{array}{c}\text { Hemo-dynamic } \\
\text { para-meters }\end{array}$} & $\begin{array}{c}\text { 2-d segment } \\
\text { of VA }\end{array}$ & \multicolumn{2}{|c|}{ Atlantoaxial instability (n= 36) } & \multicolumn{4}{c|}{ CG (n = 37) } \\
\cline { 2 - 7 } & Neutral & Turn left & Turn right & Neutral & Turn left & Turn right \\
\hline \multirow{2}{*}{$\begin{array}{c}\text { Vs } \\
\text { cm/sec }\end{array}$} & LVA & $43.9 \pm 4.2$ & $38.1 \pm 3.5$ & $37.3 \pm 3.6$ & $50.3 \pm 4.9$ & $47.6 \pm 4.3$ & $43.7 \pm 4.1$ \\
\cline { 2 - 8 } & RVA & $45.1 \pm 4.3$ & $37.6 \pm 3.2$ & $38.2 \pm 3.7$ & $48.5 \pm 4.7$ & $46.9 \pm 4.5$ & $46.2 \pm 4.3$ \\
\hline \multirow{2}{*}{ RI } & LVA & $0.61 \pm 0.02$ & $0.63 \pm 0.02$ & $0.62 \pm 0.02$ & $0.57 \pm 0.02$ & $0.61 \pm 0.03$ & $0.59 \pm 0.02$ \\
\cline { 2 - 8 } & RVA & $0.62 \pm 0.02$ & $0.64 \pm 0.02$ & $0.63 \pm 0.02$ & $0.59 \pm 0.02$ & $0.63 \pm 0.02$ & $0.59 \pm 0.02$ \\
\hline \multirow{2}{*}{ PI } & LVA & $0.88 \pm 0.05$ & $0.89 \pm 0.06$ & $0.90 \pm 0.06$ & $0.83 \pm 0.04$ & $0.84 \pm 0.04$ & $0.85 \pm 0.04$ \\
\cline { 2 - 8 } & RVA & $0.89 \pm 0.04$ & $0.91 \pm 0.06$ & $0.94 \pm 0.06$ & $0.87 \pm 0.04$ & $0.91 \pm 0.05$ & $0.89 \pm 0.04$ \\
\hline \multirow{2}{*}{$\begin{array}{c}\text { Vvol, } \\
\text { ml/min }\end{array}$} & LVA & $115 \pm 13$ & $107 \pm 12$ & $105 \pm 11$ & $129 \pm 14$ & $128 \pm 12$ & $119 \pm 13$ \\
\cline { 2 - 8 } & RVA & $114 \pm 11$ & $104 \pm 10$ & $103 \pm 9$ & $118 \pm 11$ & $112 \pm 11$ & $114 \pm 12$ \\
\hline
\end{tabular}

Table 1: Parameters of the second segment of vertebral arteries (VA) hemodynamics in a patients with atlantoaxial instability and comparative group (CG) in a neutral position and with head rotation.

Among patients with atlantoaxial instability in the neutral position and with head rotation, the values of Vs (range $37.3 \mathrm{~cm} / \mathrm{sec}$ $-45.1 \mathrm{~cm} / \mathrm{sec}$ ) and minute flow volume - MFV (range $103-115 \mathrm{ml} /$ $\min$ ) were lower, and the indices resistance - RI (0.61-0.63) and pulsation - PI (0.88-0.94) more than in healthy people. The difference between hemodynamic parameters in the second segment of the vertebral arteries in patients with atlantoaxial instability and healthy individuals was not significant (Table 1).

At the level of the 3rd segment of the vertebral artery, Vs among healthy individuals in different head positions varied within 43.5$49.5 \mathrm{~cm} / \mathrm{sec}$, RI - 0.57-0.62, PI - 0.82-0.91, MFV - 109-125 ml/min. When comparing the hemodynamic parameters of the second and third segments of the vertebral arteries in healthy individuals, both in a neutral position and during head rotation, no significant differences were found. Among patients with atlantoaxial instability in the neutral position, Vs and MFV were insignificantly lower than in healthy subjects, and RI and PI were higher than in healthy subjects. Vs of the left VA with ipsilateral head rotation (Turn left) was $36.7 \pm 3.8 \mathrm{~cm} / \mathrm{sec}$, with contralateral rotation (turn right) $-57.3 \pm$ $5.2 \mathrm{~cm} / \mathrm{sec}(\mathrm{P} \mathrm{rl}<0.01)$, in healthy individuals $-46.1 \pm 4.2 \mathrm{~cm} / \mathrm{sec}$ and $44.3 \pm 4.1 \mathrm{~cm} / \mathrm{sec}(\mathrm{P}<0.05)$. In the right VA with ipsilateral rotation, Vs was $37.4 \pm 3.6 \mathrm{~cm} / \mathrm{sec}$, significantly (P lva-rva < 0.01) less than in the left VA with contralateral rotation.

The RI in the left VA was highest during contralateral head rotation and amounted to $0.71 \pm 0.03$, which is significantly $(\mathrm{P}<0.01)$ higher than in healthy individuals. The same trend in the dynamics of hemodynamic parameters was observed in the right vertebral artery. With contralateral rotation (turn left), Vs in the right VA was $54.9 \pm 5.1 \mathrm{~cm} / \mathrm{sec}$, with ipsilateral rotation (turn right) $-37.4 \pm 3.6$ $\mathrm{cm} / \mathrm{sec}(\mathrm{P} \mathrm{lr}<0.01)$, and in the comparative group $-47.8 \pm 4.3 \mathrm{~cm} /$ sec. The RI in the right VA with contralateral head rotation was $0.70 \pm 0.03$, and with ipsilateral rotation it was $0.69 \pm 0.03$, which is significantly $(\mathrm{P}<0.05)$ higher than in healthy individuals. PI had the highest value in the left VA during contralateral head rotation and was $1.05 \pm 0.07$, which is significantly $(P<0.05)$ higher than in healthy individuals (Figure 1, 2). The smallest MFV was also recorded in the left VA during contralateral head rotation and was 92 $\pm 10 \mathrm{ml} / \mathrm{min}$ - significantly $(\mathrm{P}<0.05$ ) less than in healthy individuals (Table 2).

In previous studies, the hemodynamic parameters of blood flow in the vertebral arteries at the level of the atlanto-axial joint in different functional tests were studied. Cui K. Q. and others. studied blood circulation in the third segment of the vertebral artery in 6 monkeys in different functional tests [10]. The very small number of observations makes it difficult to obtain statistically reliable data and use them to compare with the results of human studies. Erhardt J.W. and co-authors also studied the blood flow in the vertebral arteries at the level of the atlanto-axial joint with a rapid push into the occipital part of the head in volunteers. They studied the change in blood flow velocity and resistance index before and after shock [8]. Bulut MD., et al. hemodynamic parameters of blood flow in the vertebral arteries before and after manual therapy were studied. The authors established a positive dynamics in the systolic blood flow velocity in the vertebral artery after manipulation [7]. 


\begin{tabular}{|c|c|c|c|c|c|c|c|}
\hline \multirow{2}{*}{$\begin{array}{c}\text { Hemo-dynamic } \\
\text { para-meters }\end{array}$} & \multirow{2}{*}{$\begin{array}{c}\text { 3-d } \\
\text { segment of VA }\end{array}$} & \multicolumn{3}{|c|}{ Atlantoaxial instability $(n=36)$} & \multicolumn{3}{|c|}{ CG $(n=37)$} \\
\hline & & Neutral & Turn left & Turn right & Neutral & Turn left & Turn right \\
\hline \multirow{6}{*}{$\begin{array}{c}\text { Vs } \\
\mathrm{cm} / \mathrm{sec}\end{array}$} & LVA & $41.6 \pm 4.3$ & $36.7 \pm 3.8$ & $57.3 \pm 5.2$ & $49.5 \pm 4.8$ & $46.1 \pm 4.2$ & $44.3 \pm 4.1$ \\
\hline & & & & $\mathrm{P}<0,05$ & & & \\
\hline & & & & P r $-\mathrm{l}<0,01$ & & & \\
\hline & & & & P lva-rva $<0,01$ & & & \\
\hline & RVA & $42.9 \pm 4.5$ & $54.9 \pm 5.1$ & $37.4 \pm 3.6$ & $47.4 \pm 4.6$ & $47.8 \pm 4.3$ & $43.5 \pm 3.9$ \\
\hline & & & $\mathrm{Pl}-\mathrm{r}<0,01$ & & & & \\
\hline \multirow[t]{4}{*}{ RI } & LVA & $0.62 \pm 0.02$ & $0.68 \pm 0.03$ & $0.71 \pm 0.03$ & $0.57 \pm 0.02$ & $0.61 \pm 0.03$ & $0.60 \pm 0.02$ \\
\hline & & & & $\mathrm{P}<0,01$ & & & \\
\hline & RVA & $0.63 \pm 0.02$ & $0.70 \pm 0.03$ & $0.69 \pm 0.03$ & $0.58 \pm 0.02$ & $0.62 \pm 0.02$ & $0.61 \pm 0.02$ \\
\hline & & & $\mathrm{P}<0,05$ & $\mathrm{P}<0,05$ & & & \\
\hline \multirow{3}{*}{ PI } & LVA & $0.91 \pm 0.05$ & $0.94 \pm 0.06$ & $1.05 \pm 0.07$ & $0.82 \pm 0.04$ & $0.85 \pm 0.04$ & $0.84 \pm 0.04$ \\
\hline & & & & $\mathrm{P}<0,05$ & & & \\
\hline & RVA & $0.89 \pm 0.05$ & $0.98 \pm 0.07$ & $1.01 \pm 0.07$ & $0.85 \pm 0.04$ & $0.89 \pm 0.05$ & $0.91 \pm 0.05$ \\
\hline \multirow{3}{*}{$\begin{array}{l}\text { Vvol, } \\
\mathrm{ml} / \mathrm{min}\end{array}$} & LVA & $112 \pm 12$ & $97 \pm 1$ & $92 \pm 10$ & $125 \pm 12$ & $123 \pm 12$ & $117 \pm 11$ \\
\hline & & & & $\mathrm{P}<0,05$ & & & \\
\hline & RVA & $113 \pm 11$ & $94 \pm 10$ & $96 \pm 9$ & $113 \pm 11$ & $113 \pm 11$ & $109 \pm 10$ \\
\hline
\end{tabular}

Table 2: Parameters of the third segment of vertebral arteries (VA) hemodynamics in a patients with atlantoaxial instability and comparative group (CG) in a neutral position and with head rotation.

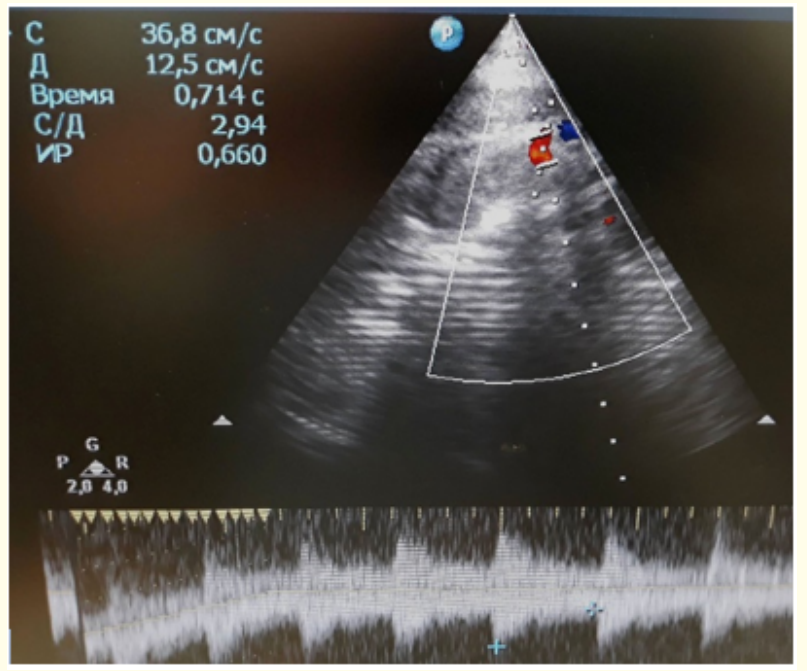

Figure 1: Doppler spectrum of the blood flow in the third segment of the left vertebral artery in a patient with atlantoaxial instability at a ipsilateral rotation of the head. The Vs is $36,8 \mathrm{~cm} / \mathrm{c}$,

$$
\text { RI - 0,66. }
$$

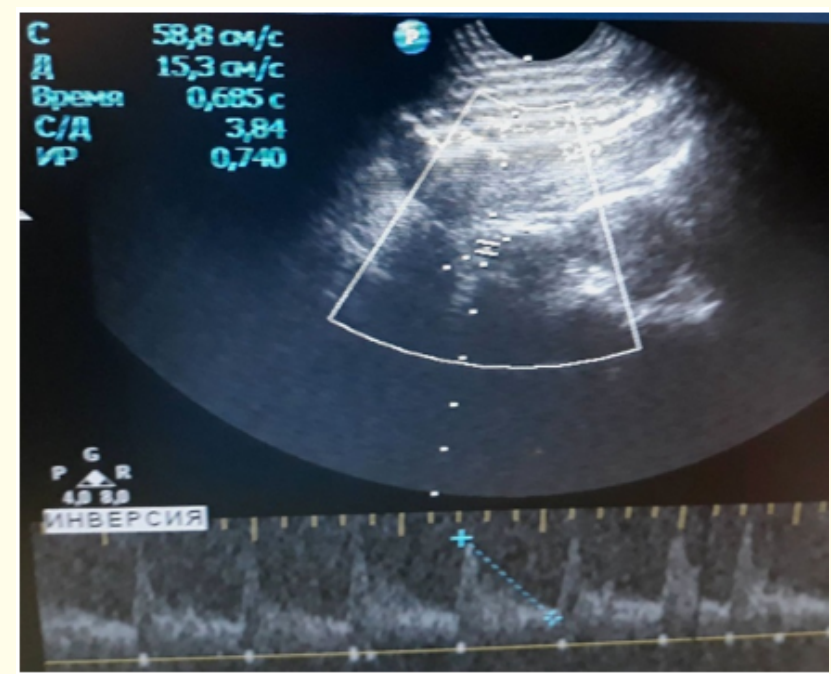

Figure 2: Doppler spectrum of the blood flow in the third segment of the right vertebral artery in a patient with atlantoaxial instability at a contrlateral rotation of the head. The Vs is 58,8 $\mathrm{cm} / \mathrm{c}, \mathrm{RI}-0,74$. 
In contrast to previous studies, in which the dynamics of systolic velocity and blood flow resistance index was studied, we also studied the pulsation index and the minute volume of blood flow. The index of pulsation, determined on the basis of the average velocity, better characterizes the tone of the vessel than the index of resistance. The minute volume of blood flow is determined taking into account the diameter of the vessel and the integral of the linear blood flow velocity. Our studies show that the choice of more effective functional tests for assessing hemodynamic parameters in the vertebral arteries and its interpretation depends on the type of instability.

Analysis of hemodynamic parameters during rotational head movements, depending on the predominant localization of the degenerative process, made it possible to more objectively evaluate the research results. It turned out that the worst hemodynamic parameters are recorded with ipsilateral head rotation in the vertebral artery of the same name.

Thus, atlantoaxial instability during rotational movements leads to hemodynamic disturbances in the vertebral arteries, which can have bad consequences in case of large overloads.

\section{Conclusion}

In atlantoaxial instability, rotational head movements lead to a deterioration in hemodynamic parameters in the third segment of the vertebral arteries in the form of a decrease in the minute volume of blood flow, an increase in resistance and pulsation indices. With ipsilateral rotation of the head, the blood flow velocity in the vertebral artery of the same name decreases, while during contralateral rotation, on the contrary, it increases. The difference in comparison between blood flow indicators on the opposite artery and the results of healthy individuals has a significant value.

\section{Bibliography}

1. Cummings KR., et al. "Radiographic indices for the diagnosis of atlantoaxial instability in toy breed dogs [corrected]". Veterinary Radiology and Ultrasound 59.6 (2018): 667-676.

2. Kothe R. "Rheumatoid instability in the cervical spine: Diagnostic and therapeutic strategies". Orthopade 47.6 (2018): 489-495.

3. Macovei LA and Rezuş E. "Cervical spine lesions in rheumatoid arthritis patients". Revista Medico-Chirurgicala a Societatii de Medici si Naturalisti din Iasi 120.1 (2016): 70-76.
4. Lyons C., et al. "Atlantoaxial Instability in a Patient with Neck Pain and Ankylosing Spondylitis". Military Medicine 183.9-10 (2018): e654-e657.

5. Mitchell J. "Vertebral Artery Blood flow Velocity Changes Associated with Cervical Spine rotation: A Meta-Analysis of the Evidence with implications for Professional Practice". Journal of Manipulative and Physiological Therapeutics 17.1 (2009): 46-57.

6. Albuquerque FC., et al. "Craniocervical arterial dissections as sequelae of chiropractic manipulation: patterns of injury and management". Journal of Neurosurgery 115.6 (2011): 11971205.

7. Bulut MD., et al. "Decreased Vertebral Artery Hemodynamics in Patients with Loss of Cervical Lordosis". Medical Science Monitor 15.22 (2016): 495-500.

8. Brett A., et al. "The immediate effect of atlanto-axial high velocity thrust techniques on blood flow in the vertebral artery: A randomized controlled trial". Musculosceletal Science and Practice 20.4 (2015): 614-622.

9. Yelverton C., et al. "Changes in vertebral artery blood flow in different head positions and post cervical manipulative therapy". Journal of Manipulative and Physiological Therapeutics 43.2 (2020): 144-151.

10. Cui KQ., et al. "Comparison of atlanto-axial artery hemodynamics during cervical spine manipulation with Doppler ultrasound in rhesus macaques". International Journal of Clinical and Experimental Medicine 9.1 (2016): 209-218.

\section{Assets from publication with us}

- Prompt Acknowledgement after receiving the article

- Thorough Double blinded peer review

- Rapid Publication

- Issue of Publication Certificate

- High visibility of your Published work

Website: www.actascientific.com/

Submit Article: www.actascientific.com/submission.php

Email us: editor@actascientific.com

Contact us: +919182824667 